\title{
Clinical significance of immunocytochemistry for PIK3CA as a carcinogenesis-related marker on liquid-based cytology in cervical intraepithelial neoplasia
}

\author{
TOMOKO GOTO ${ }^{1}$, MASASHI TAKANO ${ }^{2}$, HIDENORI SASA ${ }^{2}$, HITOSHI TSUDA ${ }^{3}$, \\ KAZUHIRO YAMAUCHI ${ }^{4}$ and YOSHIHIRO KIKUCHI ${ }^{2}$
}

\author{
${ }^{1}$ Department of Obstetrics and Gynecology, Saitama Medical College, 38 Morohongo, Moroyama-cho, Iruma-gun, \\ Saitama 350-0495; Departments of ${ }^{2}$ Obstetrics and Gynecology, ${ }^{3}$ Pathology II, National Defense Medical College, \\ 3-2 Namiki, Tokorozawa, Saitama 359-8513; ${ }^{4}$ Pathology and Cytology Center, \\ PCL Japan, 1361-1 Matoba, Kawagoe, Saitama 350-1101, Japan
}

Received July 11, 2005; Accepted September 13, 2005

\begin{abstract}
The catalytic subunit $\alpha$ of phosphatidylinositol 3-kinase (PIK3CA) has been expected to play a role as an important oncogene in uterine cervical carcinoma, whose expression in non-invasive lesions has received considerable attention. We investigated the potential of PIK3CA as a carcinogenesis-related marker for early intraepithelial lesion of the uterine cervix in cytology samples. Seventy-four cases with abnormal cytology suggesting the existence of cervical intraepithelial neoplasia (CIN) lesions, whose findings were histologically confirmed, were selected; they consisted of 20 CIN1, 21 CIN2, and 33 CIN3, respectively. In addition, 17 normal cases, whose cervical cytology revealed no abnormality over three occasions, were selected. Liquid-based cytology specimens were applied for human papillomavirus (HPV) DNA typing and immunocytochemistry using three different antibodies for p16 ${ }^{\mathrm{INK} 4 \mathrm{a}}$, Ki-67 and PIK3CA, respectively. The fraction of immunopositive cells on the slides was calculated and expressed as mean numbers. Receiver operating characteristic (ROC) plots were generated to determine the diagnostic accuracy of each immunocytochemistry test. The mean number of immunopositive cells in the CIN3 group was significantly higher than other groups for all three antibodies. Among all
\end{abstract}

Correspondence to: Dr Tomoko Goto, Department of Obstetrics and Gynecology, Saitama Medical College, 38 Morohongo, Moroyama-cho, Iruma-gun, Saitama 350-0495, Japan

E-mail:tmkgoto@aol.com

Abbreviations: CIN, cervical intraepithelial neoplasia; LBC, liquidbased cytology; HPV, human papillomavirus; HR-HPV, high-risk HPV; ROC, receiver operating characteristic; PI3K, phosphatidylinositol 3-kinase; PIK3CA, catalytic subunit $\alpha$ of PI3K; SCC, squamous cell carcinoma

Key words: cervical intraepithelial neoplasia, liquid-based cytology, immunocytochemistry, PIK3CA groups, PIK3CA showed a superior specificity to distinguish CIN3 from other groups. Comparison of three markers by ROC curves also revealed that PIK3CA provided the best method for distinguishing CIN3. Thus, expression of PIK3CA was observed in liquid-based cytology in CIN lesions, which suggested its diagnostic significance in addition to the use of routine cervical cancer smear and the HPV screening program.

\section{Introduction}

Uterine cervical cancer is one of the most common female cancers worldwide. Although a beneficial impact from cytological screening of the uterine cervix in reducing the incidence and mortality of uterine cervical cancer has been well recognized, cytology has a limited sensitivity and reproducibility as well as relatively frequent equivocal results. Also, Papanicolaou smear is affected by a certain rate of false-negative results (1). Considerable efforts have been made to improve the quality of primary screening of cervical cancer and there has been an important evolution with the introduction of new technology such as liquid-based cytology (LBC). Combination with human papillomavirus (HPV) testing has been encouraged because laboratory and epidemiological research suggests a strong association between HPV infection and cervical cancer $(2,3)$. So far, the specificity of HPV testing is not high enough to be performed well in a primary screening setting (4). There is a strong demand for additional, more sensitive and specific markers to improve screening programs. Objective and decisive biomarkers would improve standardization and quality control for the diagnosis of cervical cancer.

Immunocytochemistry provides information that is closely related to the morphological information provided by cytology and histology. This could be a useful diagnostic asset because it is relatively easy and fast. Several studies have shown the feasibility of applying p16 $6^{\mathrm{INK} 4 \mathrm{a}}$ immunocytochemistry to cervical cytology (5-7). Sahebali et al showed that p16 $16^{\mathrm{INK} 4 a}$ and Ki-67 immunocytochemistry were applied to liquid-based cytology, respectively $(8,9) \cdot \mathrm{p} 16^{\mathrm{INK} 4 \mathrm{a}}$ could have the same significant clinical utility as measuring HPV gene expression. 
Ki-67 positivity has also been found to increase with the number of positive cells in dysplasia and carcinoma and can be applied as a surrogate marker for HPV-related neoplasia (10). Although infection with HPV is known to play a crucial role in the immortalization of cervical epithelial cells, HPV infection in women does not always develop dysplasia or carcinoma (11) and the long latency of the transition from CIN3 to carcinoma strongly suggests that other factors in addition to HPV infection are required for the malignant transformation of epithelial cells (12). Mutations affecting tumor-suppressor genes or cellular oncogenes may be promoting factors.

PIK3CA encodes the $\mathrm{p} 110 \alpha$ catalytic subunit of phosphatidylinositol 3-kinase (PI3K), which is an important component of the lipid signaling pathway. The subsequent activation of the downstream serine/threonine protein kinase is involved in multiple cellular processes, including cell survival, proliferation and apoptosis, and has been related to carcinogenesis $(13,14)$. Amplification and overexpression of PIK3CA in ovarian cancer and in squamous cell carcinoma of the neck and uterine cervix have been reported (15-17). Zhang et al (18) showed that frequent amplification of PIK3CA in primary cervical tumors might be functionally involved in cervical carcinogenesis. Although screening for cervical cancer precursors has evolved due to the introduction of new technology, there is no cytological study to test the PIK3CA function immunocytochemically in a clinical setting. In the present study, the significance of immunocytochemistry of PIK3CA using liquid-based samples was studied.

\section{Materials and methods}

Cases. Of the patients who visited the Department of Obstetrics and Gynecology at the National Defense Medical College Hospital between July 2002 and December 2003, 74 cases with abnormal cytology suggesting the existence of a CIN lesion were selected for the current study. All cytological findings were histologically confirmed by punch biopsy or conization within two months of cytological evaluation. The cases with CIN consisted of 20 CIN1, 21 CIN2, and 33 CIN3, respectively. In addition, 17 normal cases were selected from patients whose cervical cytology was annually analyzed and revealed no abnormality over three occasions in our institution. A total of 91 archived liquid-based cervical cytology specimens that had been used previously for clinical purposes were applied to three thin-layer slides for immunocytochemistry and HPV-DNA testing was also performed with residual samples in approximately half of these patients. Prior to the initiation of the present study, the protocol was approved by our institutional review board. Written informed consent was obtained from all patients.

Cytology samples. Cervical cells were collected using the Cervex-Brush (Rovers, Oss, The Netherlands) and placed immediately into alcohol-based preservative (Tripath Imaging Inc., Burlington, NC, USA). From each specimen, $6 \mathrm{ml}$ was used to make 3 slides of thin layer liquid-based cytology (LBC) with the fully robotic AutoCyte PREP System (Tripath Imaging) and each slide was used for immunocytochemical staining and HPV typing.
Immunocytochemical staining and antibodies. Immunostaining for p16 ${ }^{I N K 4 A}$ primary antibody, clone E6H4 (MTM Laboratories, Heidelberg, Germany), was performed using p16 $6^{\mathrm{INK} 4 \mathrm{a}}$ Research Kit (DakoCytomation, Glostrup, Denmark). Cells were regarded as positive if both the nucleus and the cytoplasm were stained.

Immunocytochemistry was performed using the prediluted primary anti-human Ki-67 mouse monoclonal antibody (DakoCytomation, 1:150 dilution). The slides were incubated for $60 \mathrm{~min}$. Detection was accomplished using the EnVision+ system (DakoCytomation) for $60 \mathrm{~min}$ and incubation with DAB (DakoCytomation) for $5 \mathrm{~min}$. All steps were performed at room temperature and slides were washed in phosphatebuffered saline. Slides were counterstained with hematoxylin. Cells were considered immunopositive if the nucleus showed homogeneous or punctuate staining. Cytoplasmic staining without nuclear staining was not considered to be positive.

Immunocytochemistry was performed using the prediluted primary goat polyclonal antibody against PI 3-kinase $110 \alpha$ (Santa Cruz Biotechnology, Inc., CA, USA, 1:200 dilution). The slides were incubated for $60 \mathrm{~min}$, followed by labeling of LSAB+ System-HRP (DakoCytomation) and incubation with DAB (DakoCytomation) for $2 \mathrm{~min}$. Slides were counterstained with hematoxylin. Cells were considered immunopositive if the cytoplasm showed homogeneous staining.

Evaluation of immunocytochemistry. The evaluation of immunocytochemistry was made by light microscopy. The staining intensity was not graded to avoid subjective interpretation. All cells in three high power fields (x400), which were considered to be representative of the whole cell area, were counted and the total amount of cells on the slide was calculated. This referred to the Bethesda system 2001 concerning the assessment of LBC cellularity (19). All positively stained cells in the whole cell area were counted and the fraction of positive cells on the slide was calculated by two independent pathologists with no knowledge of the patient's clinical information. This fraction was expressed as the number of immunopositive cells/1000 cells to compare the results of all samples.

$H P V-D N A$ detection and typing. The remaining cell suspension was transferred to an Eppendorf tube and the cells were pelleted by centrifugation. DNA extraction was performed using QiaAmp DNA Blood Mini Kit (Qiagen, Tokyo, Japan) and its protocol. The DNA extracts were stored at $-20^{\circ} \mathrm{C}$ until PCR was carried out. All samples were tested with L1-PCR consensus primers (L1C1, 5'-CGTAAACGTTTTCCCTATT TTTTT-3'; L1C2, 3'-GTTATGTCTCATAAATCCCAT-5') (20). Typing of HPV-DNA was performed by the restriction fragment length polymorphism method and was carried out with type-specific PCRs for high-risk HPV (HR-HPV) types (HPV6, 11, 16, 18, 30, 31, 33, 34, 39, 42, 43, 44, 45, 51, 52, $53,54,55 \mathrm{a}, 55 \mathrm{~b}, 56,58,59,61,66)$. Samples that were positive for the consensus PCR but negative for the type specific primers were classified as unidentified HPV genotypes of unknown malignant potential.

Statistical analysis. Data were analyzed using the software package, STATMATE III (Atoms, Tokyo, Japan). A p-value $<0.05$ was considered to be statistically significant. All 


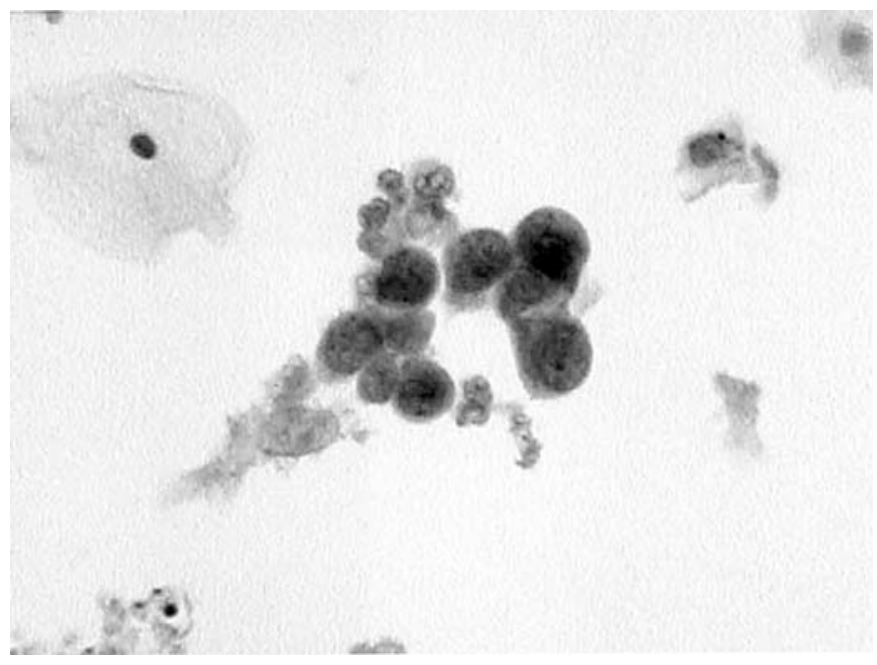

Figure 1. Representative immunopositive dysplastic cells for PIK3CA in a case of severe dysplasia. $\mathrm{x} 40$.

analyzed data are expressed as the mean number of immunopositive cells per 1000 cells and standard error of the mean (SEM). Receiver operating characteristic (ROC) plots were generated to determine the diagnostic accuracy of each immunocytochemistry test for CIN3 compared to CIN1, CIN2 and normal. The curve which comes close to the ideal values of $100 \%$ sensitivity and $100 \%$ specificity, which is the top left corner of the ROC graph, provided the best combination of sensitivity and specificity, assuming an equal importance of each. ROC curves were used to further establish optimal thresholds.

\section{Results}

Immunostaining. Immunopositive cells for $\mathrm{p} 16^{\text {INK4a }}$ exhibited a medium-brown cytoplasm with a darker brown nucleus. Cytoplasmic staining was diffuse. Immunoreactive cells for Ki-67 showed dark brown, homogeneous or punctuated staining, limited exclusively to the nucleus. Immunopositivity for PIK3CA exhibited medium-brown homogeneous staining localized to the cytoplasm (Fig. 1).
Table I. The study population.

\begin{tabular}{lccc}
\hline & $\begin{array}{c}\text { Number } \\
(\%)\end{array}$ & $\begin{array}{c}\text { Mean age } \\
\text { (range) }\end{array}$ & $\begin{array}{c}\text { HR-HPVa/ } \\
\text { HPV positive/ } \\
\text { HPV negative (\%) }\end{array}$ \\
\hline Normal & $17(18.7)$ & $38(27-55)$ & $17 / 33 / 67$ \\
CIN1 & $20(22.0)$ & $38(21-54)$ & $42 / 67 / 33$ \\
CIN2 & $21(23.1)$ & $36(22-52)$ & $50 / 58 / 42$ \\
CIN3 & $33(36.3)$ & $38(26-57)$ & $58 / 67 / 33$ \\
Total & 91 & 38 & $45 / 60 / 40$ \\
\hline
\end{tabular}

${ }^{a} \mathrm{HR}-\mathrm{HPV}$, high-risk human papillomavirus .

Cytological diagnosis. Table I shows the distribution of the study group into CIN categories together with their age distribution and the number of infectious cases with HR-HPV types. The mean number of cells on a slide was $16,970(95 \%$ $\mathrm{CI}=15,005-18,936)$.

p16 INK4a immunostaining. When comparing the number of p16 ${ }^{\text {INK4a }}$ immunopositive cells/1000 cells between the different CIN groups, the CIN3 group showed a significantly higher count (mean, 7.27; SEM, 1.30) than the normal group (mean, 0.35; SEM, 0.19; p<0.001), the CIN1 group (mean, 0.87; SEM, 0.31; $<<0.001$ ) and the CIN2 group (mean, 2.03; SEM, 0.44; $\mathrm{p}<0.01$ ) (Fig. 2). In addition, the CIN2 group showed a significantly higher count of immunopositive cells than the normal group $(\mathrm{p}<0.01)$.

Ki-67 immunostaning. When comparing the number of Ki-67 immunopositive cells/1000 cells between the different CIN groups, the CIN3 group showed a significantly higher count (mean, 6.31; SEM, 0.98) than the normal group (mean, 0.58; SEM, 0.20; $<<0.001$ ), CIN1 group (mean, 2.34; SEM, 058; $\mathrm{p}<0.01$ ) and CIN2 group (mean, 2.23; SEM, 0.72; $\mathrm{p}<0.01$ ) (Fig. 2). The CIN1 and CIN2 group also showed higher mean counts of immunopositive cells than the normal group $(\mathrm{p}<0.05)$.

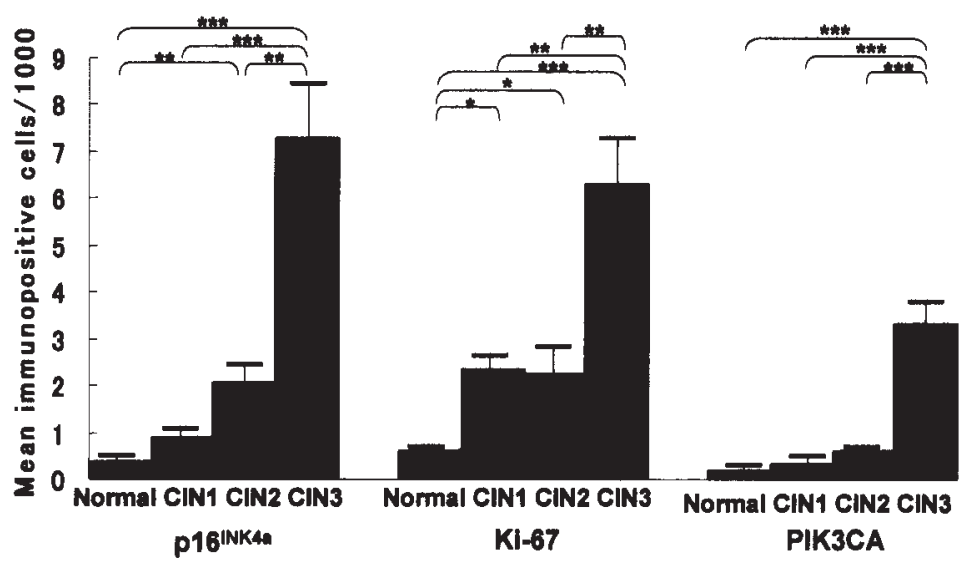

Figure 2. Mean number and standard error of the mean (SEM) of immunopositive cells/1000 cells were shown in normal and CIN lesions. Immunopositive cell counts in the CIN3 group were significantly higher than all other groups in each method. PIK3CA especially showed superior specificity to distinguish CIN3 from other groups. ${ }^{*} \mathrm{p}<0.05,{ }^{* *} \mathrm{p}<0.01,{ }^{* * *} \mathrm{p}<0.001$. 


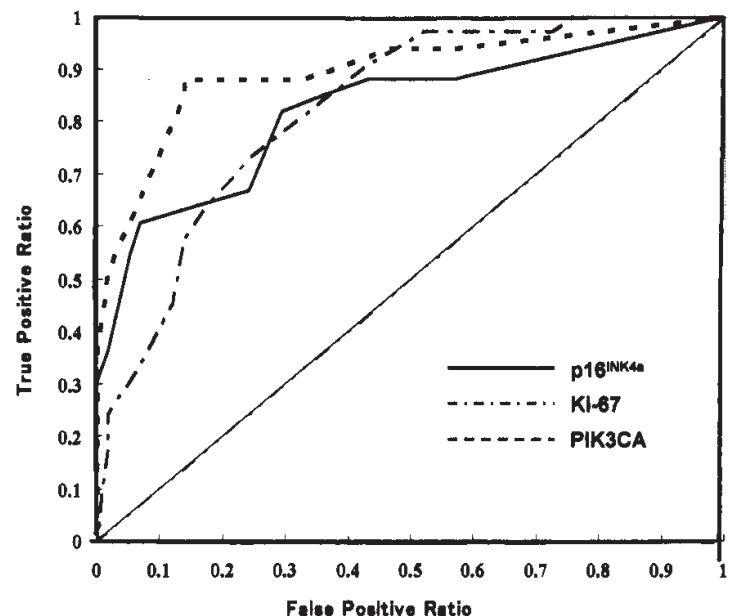

Figure 3. Receiver operating characteristic (ROC) curves of each immunocytochemistry test for CIN3 compared to CIN1, CIN2 and normal. Based on the curve closest to the top left corner of the graph, PIK3CA provided the best method for distinguishing CIN3.

PIK3CA immunostaining. When comparing the number of PIK3CA immunopositive cells/1000 cells between the different CIN groups, the CIN3 group showed a significantly higher count (mean, 3.29; SEM, 0.60; p<0.001) than all other groups, including normal (mean, 0.19; SEM, 0.14), CIN1 (mean, 0.31; SEM, 0.09) and CIN2 groups (mean, 0.61; SEM, 0.13) (Fig. 2). Comparative to p16 $6^{\mathrm{INK} 4 \mathrm{a}}$ and Ki-67, PIK3CA showed superior specificity to distinguish CIN3 from other groups, especially CIN2.

HPV-DNA typing and immunopositive count. The HR-HPVpositive group showed significantly higher mean $\mathrm{p} 16^{\mathrm{INK} 4 \mathrm{a}}$ immunopositive cell counts (mean, 7.71; SEM, 1.66) in CIN3 lesions than the HPV-negative group (mean, 5.63; SEM, 0.82; $\mathrm{p}<0.05)$. There were no significant differences for Ki-67 and PIK3CA immunopositive cells between HR-HPV-positive and -negative groups (data not shown).

Diagnostic accuracy. To determine the ability of each immunocytochemistry, ROC plots were generated to illustrate the diagnostic accuracy of the test (Fig. 3). Sensitivity and specificity were calculated between the CIN3 group and other groups for each immunocytochemistry test. Based on the curve closest to the top left corner of the graph, PIK3CA provided the best method for distinguishing CIN3. Table II gives the AUCs and thresholds for $95 \%$ sensitivity and $95 \%$ specificity. PIK3CA showed a higher value of AUC (0.90) than p16 $6^{\mathrm{INK} 4 \mathrm{a}}$ $(0.82)$ and Ki-67 (0.83) with relatively even $95 \%$ sensitivity and $95 \%$ specificity.

\section{Discussion}

To date, no reliable molecular marker exists to predict the malignant potential of precancerous lesions in the uterine cervix. Traditional morphological methods, such as grading of dysplastic lesions, often fail in predicting which lesion may progress in time. The causal relationship between HPV infection and cervical dysplasia/carcinoma is well established. However, only $10 \%$ of infected women develop cervical
Table II. Each immunocytochemistry test performance for CIN3 compared to CIN1, CIN2 and normal as indicated by ROC ${ }^{\text {a }}$ plotting.

\begin{tabular}{cccc}
\hline & p16 ${ }^{\mathrm{INK4a}}$ & Ki-67 & PIK3CA \\
\hline 95\% sensitivity & & & \\
Specificity (\%) & 18 & 48 & 41 \\
Threshold $^{\mathrm{b}}$ & 0.10 & 0.80 & 0.07 \\
95\% specificity & & & \\
Sensitivity (\%) & 51 & 33 & 51 \\
Threshold & 5.4 & 7.1 & 1.9 \\
AUC ${ }^{\mathrm{d}}$ (95\% CI) & 0.82 & 0.83 & 0.90 \\
& $(0.74-0.90)$ & $(0.75-0.90)$ & $(0.83-0.96)$ \\
\hline
\end{tabular}

${ }^{a}$ ROC, receiver operating characteristic. ${ }^{b}$ At $95 \%$ sensitivity the corresponding specificity is given and vice versa. ${ }^{\mathrm{c}}$ Threshold values given in number of immunopositive cells/1000 cells. ${ }^{\mathrm{d}} \mathrm{AUC}$, area under the curve, indicates diagnostic accuracy.

dysplasia $(21,22)$. HPV-DNA testing seems to be useful in the triage of difficult cases but, as a screening device, it lacks specificity $(4,23) \cdot \mathrm{p} 16^{\mathrm{INK} 4 \mathrm{a}}$ immunocytochemistry could be used as a surrogate marker for HR-HPV infection $(5-7,9)$. In our results, p16 $6^{\text {INK4a }}$ immunopositive cells in LBC for CIN3 were higher in the HR-HPV-positive group than in the negative group. The infection of cervical cells by HPV manifests itself in changes in the function or expression of host genes, and the detection of these alterations can play a role in screening and diagnosis. Actually, mild cytological abnormalities are extremely common in young women, but most of these lesions regress spontaneously, even when caused by oncogenic types of HPV $(24,25)$ which play a crucial role in the pathogenesis of cervical cancer. This has prompted efforts to discover other biomarkers and other screening techniques with the potential to supplement cytological screening. Accordingly, there is a need to explore the screening system detecting women with lesions that need medical intervention, such as CIN3, but $\mathrm{p} 16^{\mathrm{INK} 4 \mathrm{a}}$ does not seem to be suitable for this because of its lower specificity. The development of assays with high specificity for detecting cancer precursors as well as high sensitivity would represent an attractive alternative as primary screening tests or as tests to complement cytology and HPV typing.

Redon et al (17) identified the PIK3CA gene as the most likely oncogene to be overexpressed as a consequence of $3 q$ gain. PIK3CA, encoding the catalytic subunit p110 $\alpha$ of PI3-kinase 1A, has recently been suggested to play a critical role as an oncogene in ovarian and cervical cancer $(15,16)$. Information about abnormal PIK3CA gene status in squamous cell carcinoma (SCC) has predominantly been obtained from experiments on cell lines. Employing ovarian carcinoma cell lines and uterine cervix SCC cell lines, they both pointed out that increased PI3K activity is solely caused by gene-dependent overexpression of the catalytic subunit p110 $\alpha$. Woenckhaus et al (26) showed that not only invasive SCCs in the head and neck but also high-grade dysplasias showed PIK3CA copy number gain, providing strong evidence that genomic gain of $3 q 26$ is involved in the progression from high-grade 
dysplasia to invasive SCC. In the study of Heselmeyer et al (27), which performed CGH and DNA cytometry on dysplasia and carcinomas of the uterine cervix, chromosome $3 \mathrm{q}$ gain was suggested to represent a key lesion in the transition from pre-invasive neoplasia to invasive SCC of the uterine cervix. The increase of PIK3CA DNA in dysplasia may provide an initial growth advantage to the cell. However, to date, there is no information about the genetic and post-transcriptional status of PIK3CA within premalignant lesions of uterine cervical cancer.

To our knowledge, the present study is the first report to examine PIK3CA status in LBC samples. PIK3CA was significantly highly expressed in the protein level by immunocytochemistry in CIN3 lesions. The possibility of using PIK3CA to identify cytological abnormalities and function as a surrogate marker for discriminating precancerous lesions was investigated. By applying ROC, we established that discernment of CIN3 can be achieved with the highest combined sensitivity and specificity in PIK3CA immunopositive cell counts. PIK3CA immunocytochemistry might help to reduce the number of patients whose abnormal intraepithelial lesions do not need to be followed because of their lower malignancy potential. In our study, p16 $6^{\mathrm{INK} 4 \mathrm{a}}$ and Ki-67 also showed high cell counts of immunopositivity in CIN3 lesions but not as high as PIK3CA. From the results of HPV typing, Ki-67 and PIK3CA immunopositive cell counts were not related to HR-HPV infection, which suggests the utility of adjunct tools to HPV-DNA testing for Ki-67 immunocytochemistry in reflecting their potential of cell growth and PIK3CA as a carcinogenesis-related marker in early precancerous lesions. In conclusion, the diagnostic accuracy of PIK3CA to distinguish CIN3 was shown to be the best method among three markers to use as an adjunct method to LBC and HPV testing. Although these results need to be studied in a prospective situation, tests can be performed on the same sample concurrently and might be able to automate the staining procedure including counting of immunopositive cells.

\section{References}

1. Bemstein SJ, Sanchez-Ramos L and Ndubisi B: Liquid-based cervical cytologic smear study and conventional Papanicolaou smears: a metaanalysis of prospective studies comparing cytologic diagnosis and sample adequacy. Am J Obstet Gynecol 185: 308-317, 2001

2. Zur Hausen H: Advances in Viral Oncology. Vol. 8. Raven, New York, pp1-26, 1989.

3. Bosch FX, Manos MM, Munoz N, Sherman M, Jansen AM, Peto J, Schiffman MH, Moreno V, Kurman R and Shah KV: Prevalence of human papillomavirus in cervical cancer: a worldwide perspective. International Biological Study on Cervical Cancer (IBSCC) Study Group. J Natl Cancer Inst 87: 796-802, 1995.

4. Miller AB: Natural history of cervical human papillomavirus infections. Lancet 357: 1816, 2001.

5. Bibbo M, Klump WJ, De Cecco J and Kovatich AJ: Procedure for immunocytochemical detection of P16INK4A antigen in thin-layer, liquid-based specimens. Acta Cytol 46: 25-29, 2002.

6. Saqi A, Pasha TL, McGrath CM, Yu GH, Zhang P and Gupta P: Overexpression of p16INK4A in liquid-based specimens (SurePath) as marker of cervical dysplasia and neoplasia. Diagn Cytopathol 27: 365-370, 2002.

7. Murphy N, Ring M, Killalea AG, Uhlmann V, O'Donovan M, Mulcahy F, Turner M, McGuinness E, Griffin M, Martin C, Sheils O and O'Leary JJ: p16INK4a as a marker for cervical dyskaryosis: CIN and cGIN in cervical biopsies and ThinPrep smears. J Clin Pathol 56: 56-63, 2003.
8. Sahebali S, Depuydt CE, Segers K, Vereecken AJ, van Marck E and Bogers JJ: Ki-67 immunocytochemistry in liquid based cervical cytology: useful as an adjunctive tool? J Clin Pathol 56: 681-686, 2003.

9. Sahebali S, Depuydt CE, Segers K, Moeneclaey LM, Vereecken AJ, van Marck E and Bogers JJ: P16INK4a as an adjunct marker in liquid-based cervical cytology. Int J Cancer 108: 871-876, 2004.

10. Brown DC and Gatter KC: Ki67 protein: the immaculate deception? Histopathology 40: 2-11, 2002.

11. Hildesheim A, Schiffman MH, Gravitt PE, Glass AG, Greer CE, Zhang T, Scott DR, Rush BB, Lawler P, Sherman ME, Hurman RJ and Manos MM: Persistence of type-specific human papillomavirus infection among cytologically normal women. J Infect Dis 169: 235-240, 1994.

12. Zur Hausen H: Disrupted dichotomous intracellular control of human papillomavirus infection in cancer of the cervix. Lancet 343: 955-957, 1994.

13. Rameh LE and Cantley LC: The role of phosphoinositide 3-kinase lipid products in cell function. J Biol Chem 274: 8347-8350, 1999.

14. Tlsty TD: A molecular blueprint for targeting cancer? Nat Genet 21: 64-65, 1999.

15. Shayesteh L, Lu Y, Kuo WL, Baldocchi R, Godfrey T, Collins C, Pinkel D, Powell B, Mills GB and Gray JW: PIK3CA is implicated as an oncogene in ovarian cancer. Nat Genet 21: 99-102, 1999.

16. Ma YY, Wei SJ, Lin YC, Lung JC, Chang TC, Whang-Peng J, Liu JM, Yang DM, Yang WK and Shen CY: PIK3CA as an oncogene in cervical cancer. Oncogene 19: 2739-2744, 2000.

17. Redon R, Muller D, Caulee K, Wanherdrick K, Abecassis J and Du Manoir S: A simple specific pattern of chromosomal aberrations at early stages of head and neck squamous cell carcinomas: PIK3CA but not p63 gene as a likely target of 3q26-qter gains. Cancer Res 15: 4122-4129, 2001.

18. Zhang A, Maner S, Betz R, Angstrom T, Stendahl U, Bergman F, Zetterberg A and Wallin KL: Genetic alterations in cervical carcinomas: frequent low-level amplifications of oncogenes are associated with human papillomavirus infection. Int J Cancer 101: 427-433, 2002.

19. Solomon D, Davey D, Kurman R, Moriarty A, O'Connor D, Prey M, Raab S, Sherman M, Wilbur D, Wright T Jr and Young N: The 2001 Bethesda System: terminology for reporting results of cervical cytology. JAMA 287: 2114-2119, 2002.

20. Yoshikawa H, Kawana T, Kitagawa K, Mizuno M, Yoshikura H and Iwamoto A: Detection and typing of multiple genital human papillomaviruses by DNA amplification with consensus primers. Jpn J Cancer Res 82: 524-531, 1991.

21. Ho GY, Bierman R, Beardsley L, Chang CJ and Burk RD: Natural history of cervicovaginal papillomavirus infection in young women. N Engl J Med 338: 423-428, 1998.

22. Schiffman MH, Bauer HM, Hoover RN, et al: Epidemiologic evidence showing that human papillomavirus infection causes most cervical intraepithelial neoplasia. J Natl Cancer Inst 85: 958-964, 1993.

23. The Atypical Squamous Cells of Undetermined Significance/ Low-Grade Squamous Intraepithelial Lesions Triage Study (ALTS) Group: Human papillomavirus testing for triage of women with cytologic evidence of low-grade squamous intraepithelial lesions: baseline data from a randomized trial. J Natl Cncer Inst 92: 397-402, 2000.

24. Castle PE, Wacholder S, Lorincz AT, Scott DR, Sherman ME, Glass AG, Rush BB, Schussler JE and Schiffman M: A prospective study of high-grade cervical neoplasia risk among human papillomavirus-infected women. J Natl Cancer Inst 94: 1406-1414, 2002.

25. Castle PE, Wacholder S, Sherman ME, Lorincz AT, Glass AG, Scott DR, Rush BB, Demuth F and Schiffman M: Absolute risk of a subsequent abnormal pap among oncogenic human papillomavirus DNA-positive cytologically negative women. Cancer 95: 2145-2151, 2002

26. Woenckhaus J, Steger K, Werner E, Fenic I, Gamerdinger U, Dreyer T and Stahl U: Genomic gain of PIK3CA and increased expression of p110alpha are associated with progression of dysplasia into invasive squamous cell carcinoma. J Pathol 198: 335-342, 2002.

27. Heselmeyer K, Schrock E, Du Manoir S, Blegen H, Shah K, Steinbeck R, Auer G and Ried T: Gain of chromosome 3q defines the transition from severe dysplasia to invasive carcinoma of the uteine cervix. Proc Natl Acad Sci USA 93: 479-484, 1996. 